\title{
BEHAVIOUR OF STRAIN-HARDENING CEMENT-BASED COMPOSITES (SHCC) UNDER FORCE-CONTROLLED CYCLIC LOADING
}

\author{
STEFFEN MÜLLER ${ }^{1}$, VIKTOR MECHTCHERINE ${ }^{2}$ \\ ${ }^{1}$ TU Dresden, Institute of Construction Materials \\ Dresden, Germany \\ e-mail: steffen.mueller@tu-dresden \\ ${ }^{2}$ TU Dresden, Institute of Construction Materials \\ Dresden, Germany \\ e-mail:mechtcherine@tu-dresden.de
}

Key words: SHCC, ECC, cyclic loading, tension, alternating loading, failure mechanisms

\begin{abstract}
The safe use of strain-hardening cement-based composites (SHCC) for structural and nonstructural applications often requires a solid knowledge of the mechanical performance of this material under cyclic loading. In the previous investigations the behaviour of SHCC subjected to a deformation-controlled tension and tension-compression regimes was studied. The article at hand presents the experimental results obtained from the fatigue tests performed with a fixed force level for the upper (in tension) and lower (in tension or compression) reversal points of the loading cycles. The varying parameters under investigation were the upper and the lower stress levels. Moreover, two different definitions for the upper force level were applied. In the first approach, the upper force level was fixed as a value related to the average first crack stress of the particular series (for example, $80 \%$ of that average value). In the second approach, the upper reversal point was individually defined in relation to the first crack stress of the specimen under investigation in the course of the testing process (i.e., for example, $80 \%$ of the first crack stress measured on this particular specimen). For the lower reversal point two options were used resulting in pure tension and alternating tensioncompression loading regimes, respectively.
\end{abstract}

The experiments were performed on uniaxially loaded dumbbell-shaped prisms. As expected, the number of load cycles to failure decreased with increasing upper stress level. The strain capacity increased with decrease in the upper stress level from $80 \%$ to $60 \%$ related to the first crack stress. A further reduction of the upper stress level caused no change in the strain level at failure. After mechanical testing, the crack patterns on surfaces of the specimens were analysed and optical investigations of the SHCC fracture surfaces were performed to provide insights into the failure mechanisms specific for the fatigue behaviour of SHCC. Finally, the experimental results were discussed in particular with respect to the identification and description of the decisive mechanisms determining the material performance under force-controlled loading.

\section{INTRODUCTION}

Strain-hardening cement-based composites (SHCC), also often called engineered cementitious composites (ECC), are a particular type of fibre reinforced concrete (FRC), which exhibits a tensile strain capacity of several percent [1]. The name SHCC describes a specific stress-strain behaviour of this material in monotonic uniaxial tension tests. After a linear-elastic stage prior to first cracking, a stress-strain curve changes its inclination dramatically due to gradual formation of a great number of fine cracks 
bridged by polymeric fibres. The increase in stress and formation of new cracks continues until the crack-bridging capacity of the fibres in the "weakest" crack is reached. Then the final crack forms and the material exhibits strainsoftening behaviour characteristic for the most types of FRC.

While the mechanical performance of SHCC under monotonic quasi-static and partly dynamic loading has been extensively investigated over the last two decades, see, e.g., $[2,3,4]$, only little research has been performed on the behaviour of SHCC subject to cyclic loading. However, the knowledge of the material behaviour under cyclic loading is obviously absolutely necessary for structural design, specifically for estimating the service life of many objects of modern infrastructure such as bridges, railway structures, roads, windmills etc. The use of new materials like SHCC could potentially considerably enlarge the service life and reduce costs for maintenance and repair.

In tension-compression experiments by Fukuyama et al. [5] only about five cycles were applied until the strain capacity was exhausted, while the cyclic tension response accurately reflected the corresponding curve obtained from a monotonic tension test. In contrast, Douglas and Billington [6] found that the envelope of the stress-strain curve from the cyclic tests lay below the corresponding relationship measured in the monotonic regime. The difference was particularly pronounced in the experiments with high strain rates. Jun and Mechtcherine [7] did not observe any pronounced effect of tensile cyclic loading on material performance in terms of stress-strain response. The analysis of the hysteresis of the stress-strain curves showed a decrease in the material stiffness with an increasing number of loading cycles. The hysteresis further revealed a considerable partial inelastic deformation in every loop. However, the maximum number of loading cycles in the experiments was about two thousand only, which is not representative for most structural and non-structural applications with cyclic loading as the relevant scenario. Mueller and Mechtcherine [10, 11] shared the first results on the material behaviour under a reasonably high number of loading cycles. Especially in alternating tensilecompression experiments a quite different material behaviour compared to the monotonic tension tests was observed. With a higher number of loading cycles the tensile strength and the strain capacity decreased considerably. Additionally, a lower number of cracks per meter was recorded. Such behaviour was explained with increasing signs of fibre deterioration with increasing number of load cycles.

Since in many practical cases concrete structures are loaded primary in force controlled manner, the material properties under such loading regime must be studied additionally to the behaviour under deformation controlled regime. The article at hand reports first results of force-controlled tension and tension-compression tests with various load levels.

\section{EXPERIMENTAL PROGRAMM}

\subsection{Materials and specimen preparation}

For the cyclic tests a well established SHCC composition developed at TU Dresden was chosen, e.g. [7, 10], see Table 1 . The binder was a combination of Portland cement type $42.5 \mathrm{R}$ and fly ash. Fine quartz sand with a particle size from 0.06 to $0.20 \mathrm{~mm}$ was used as aggregate. The limitation of the aggregate size is necessary to achieve a uniform fibre distribution. In order to obtain a good workability and a fine fibre distribution and to prevent bleeding of the mixture a superplasticizer and a viscosity agent were used. Furthermore, the SHCC contained 2 $\%$ by volume of PVA fibre with a diameter of $40 \mu \mathrm{m}$ and a length of $12 \mathrm{~mm}$.

Table 1: Composition of the SHCC under investigation.

\begin{tabular}{lc}
\hline Component & {$\left[\mathbf{k g} / \mathbf{m}^{3}\right]$} \\
\hline Cement CEM I 42.5 R & 505 \\
\hline Fly ash & 621 \\
\hline Quartz sand & 536 \\
\hline Water & 338 \\
\hline Superplasticizer & 10 \\
\hline Viscosity agent & 4.8 \\
\hline PVA fibres & 26 \\
\hline
\end{tabular}


When producing the SHCC, first, all dry components were homogenized in a mixer. Subsequently, water and superplasticizer were added and mixed until a fluid consistency of SHCC was achieved. Finally, the fibres were added during continuous, relatively slow mixing, followed by intensive mixing needed for a good distribution of fibres.

All specimens were cast horizontally in dumbbell-shaped metal forms with the dimensions of $24 \mathrm{~mm}$ (narrow part, $40 \mathrm{~mm}$ at the ends) $\times 40 \mathrm{~mm} \times 240 \mathrm{~mm}$. After casting the moulds were covered with plastic sheets and stored for two days in a room under controlled temperature of $22{ }^{\circ} \mathrm{C}$. After de-moulding, the specimens were placed in plastic boxes and stored in a climatic room at $20^{\circ} \mathrm{C}$ until testing. Due the addition of fibres, a plane levelling of the fresh mix in the mould was not readily achievable. In order to produce flat surfaces, the superfluous material was cut off with a circular saw after SHCC hardened.

Caused by the relatively long duration of each individual test, the test series for one produced batch took one week. To minimise influences, resulting from the different age of the samples at the time of loading all specimens were tested at an average age of 8 weeks instead of the usual testing age of 4 weeks.

\subsection{Cyclic tests}

The cyclic tests were performed in a testing machine under stable climatic conditions $\left(20^{\circ} \mathrm{C}\right.$ and $\left.65 \% \mathrm{RH}\right)$. All tests were carried out with non-rotatable fixing conditions, achieved by using stiff metal adapters and special fasthardening glue. Two LVDT's were used to measure the deformation directly on the specimen, the gauge length was $100 \mathrm{~mm}$. Additionally, the data for force, crosshead displacement, cycle number and time were recorded.

All uniaxial tension and tensioncompression tests were performed on precracked specimens. As a preliminary damage strain level of $2 \mathrm{~mm} / \mathrm{m}$ was applied in deformation-controlled regime and then the deformation was decreased until zero stress level was attained. The stress-level of $2 \mathrm{~mm} / \mathrm{m}$ occurs in most cases one visible crack in the gauge length. This was followed by the cyclic loading of the sample in force-controlled regime. The upper reversal point used in this case corresponded to a specified percentage of first crack strength. The lower reversal point was either $-8.0 \mathrm{MPa}$ in the compressive range for alternating loading regime or $0.1 \mathrm{MPa}$ in the tensile range for tensile cyclic tests. Figure 1 gives a schematic view of the test regime with alternating loading.

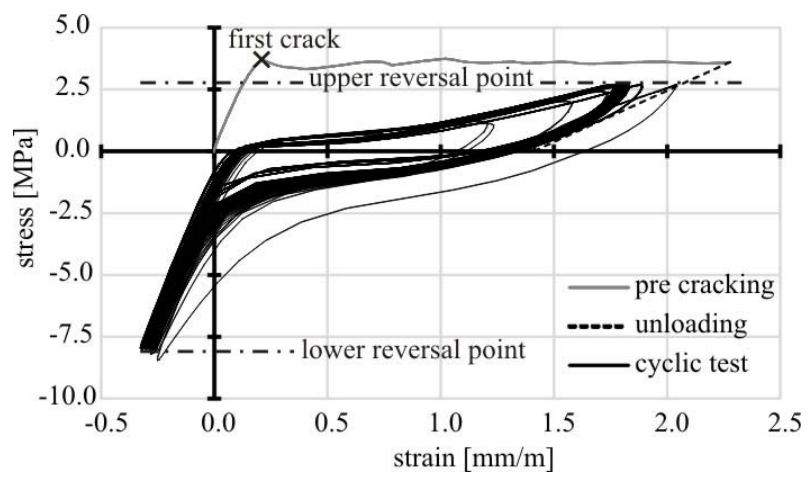

Figure 1: Schematic view of the test regime with aternating tension-compression loading.

The investigation program included tests with upper reversal points, depending a) on the individual first crack stress of the specimen, or b) on the average first crack stress of the specific mix composition. As stress levels for the upper reversal point $80 \%, 60 \%$ and $40 \%$ of first crack strength were selected. Table 2 shows the experimental program.

Table 2: Number of tested specimen per load regime

\begin{tabular}{l|cc|cc}
\hline $\begin{array}{l}\text { upper reversal } \\
\text { point in \% of } \\
\text { first crack stress/ } \\
\text { regime of lower } \\
\text { reversal point }\end{array}$ & $\begin{array}{l}\text { Individually } \\
\text { adapted } \\
\text { upper load } \\
\text { level (short } \\
\text { designation) }\end{array}$ & $\begin{array}{l}\text { Average } \\
\text { adapted } \\
\text { upper load } \\
\text { level (short } \\
\text { designation) }\end{array}$ \\
\hline $80 /$ compression & 10 & (I_80_c) & 6 & (D_80_c) \\
\hline $60 /$ compression & 5 & (I_60_c) & 6 & (D_60_c) \\
\hline $40 /$ compression & - & & 6 & (D_40_c) \\
\hline $80 /$ tension & 4 & (I_80 t) & 3 & (D_80_t) \\
\hline $60 /$ tension & - & & 2 & (D_60_t) \\
\hline $40 /$ tension & 1 & (I_40_t) & - & \\
\hline
\end{tabular}




\section{RESULTS AND DISCUSSION}

\subsection{Mechanical tests}

Pre-cracked SHCC specimens subjected to cyclic loadings with a high frequency endure a different number of load cycles depending on two main influences. On one hand, the tensile stress level for the upper reversal point plays a significant role. On the other hand, the change from purely tension swelling tests to tensioncompression alternating tests influences the bearable number of cycles essentially.

Table 3 shows the results from the tests with the upper reversal points individually adapted for each specimen in relation to its first crack stress, while Table 4 displays the results for the test series with the upper reversal point related to the average first crack stress. The tables provide information on the attained number of load cycles and the strain level at failure. Standard deviations are given in brackets.

The results provide some clear trends. The first trend was expected: A lower upper stress leads to a pronounced increase in the number of bearable load cycles. Additionally, the lower reversal point influences the results enormously, especially in the cases when the upper reversal point was related to the average values of the first crack stress. Similar trend had been reported for deformation controlled cyclic loadings with very little deformation increments [10].

Table 3: Results of tension tests with the upper reversal point set individually (standard deviations are given in parenthesis)

\begin{tabular}{lcc}
\hline $\begin{array}{l}\text { Short } \\
\text { regime } \\
\text { designation }\end{array}$ & $\begin{array}{l}\text { Number of load } \\
\text { cycles before } \\
\text { failure [-] }\end{array}$ & $\begin{array}{l}\text { Strain at } \\
\text { failure } \\
\text { [mm/m] }\end{array}$ \\
\hline I_80_c & $1,552(1,655)$ & $0.63(0.33)$ \\
\hline I_60_c & $1,840(873)$ & $0.90(0.28)$ \\
\hline I_80_t & $11,958(12,100)$ & $0.24(0.08)$ \\
\hline I_40_t & $2,979,105(-)$ & $0.07(-)$ \\
\hline
\end{tabular}

Table 4: Results of tension test with the upper reversal point related to the average first-crack stress (standard deviations are given in parenthesis)

\begin{tabular}{lcc}
\hline $\begin{array}{l}\text { Short } \\
\text { regime } \\
\text { designation }\end{array}$ & $\begin{array}{l}\text { Number of load } \\
\text { cycles before } \\
\text { failure [-] }\end{array}$ & $\begin{array}{l}\text { Strain at } \\
\text { failure } \\
\text { [mm/m] }\end{array}$ \\
\hline $\mathrm{D}$ 80_c & $444(224)$ & $1.20(0.30)$ \\
\hline $\mathrm{D}$ 60_c & $1,216(439)$ & $1.39(0.18)$ \\
\hline $\mathrm{D} \_40 \_\mathrm{c}$ & $4,672(2,138)$ & $0.93(0.11)$ \\
\hline $\mathrm{D} \_80 \_\mathrm{t}$ & $26,938(10,067)$ & $0.90(0.09)$ \\
\hline $\mathrm{D}$ 60_t & $512,251(189,350)$ & $0.34(0.01)$ \\
\hline
\end{tabular}

Figures 2 and 3 visualize the behaviour of the SHCC during cyclic tests for the loading regimes I 80 c and I 80 t, respectively. The observed differences in the material behaviour in these two regimes obviously results from the change from the pure tension to alternating tension-compression loading. The mechanism for the decrease in bearable number of cycles can be found in the increasing deterioration of fibres in the crack area: Partial pull-out of fibres during tensile cycle is followed by buckling and squashing during consecutive compressive cycle. To prove this assumption, microscopic investigations were performed on the fracture surfaces of selected specimens, see Section 3.3.

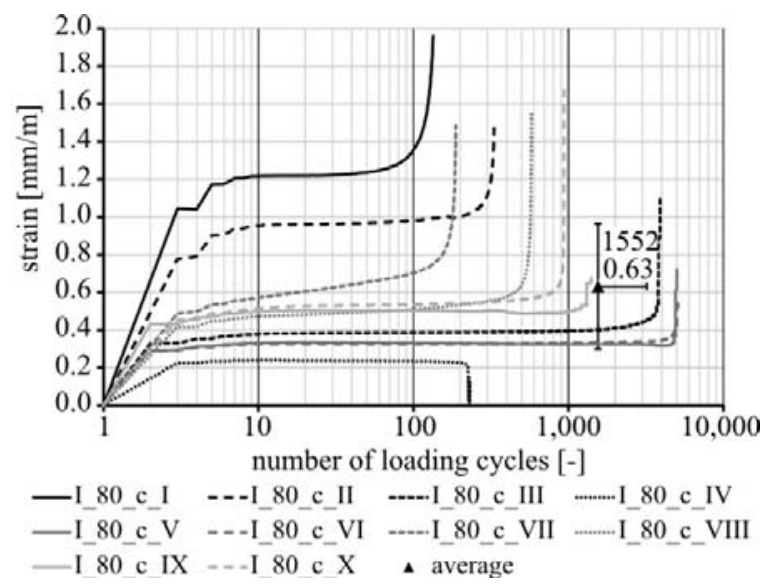

Figure 2: Stress development in the loading regime with the upper reversal point set to $80 \%$ of the individual first-crack stress and the lower reversal point in compression (regime: I_80_c) 


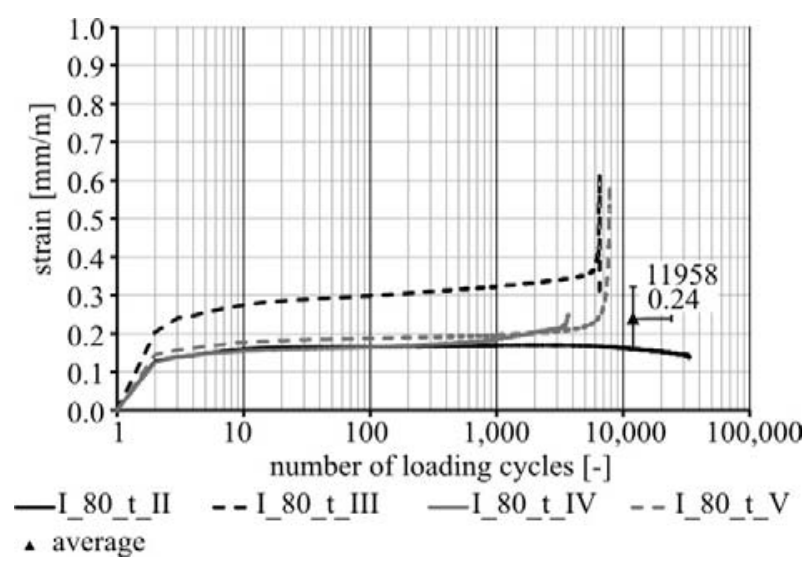

Figure 3: Stress development in the loading regime with the upper reversal point set to $80 \%$ of the individual first-crack stress and the lower reversal point in tension (regime: I_80_t)

Figures 4 and 5 display the dependency between the upper stress level and the maximum number of load cycles in tension swelling tests and in tension-compression alternating tests, respectively. The figures shows the applied upper stress level calculated for individual first crack strength of the specimen.

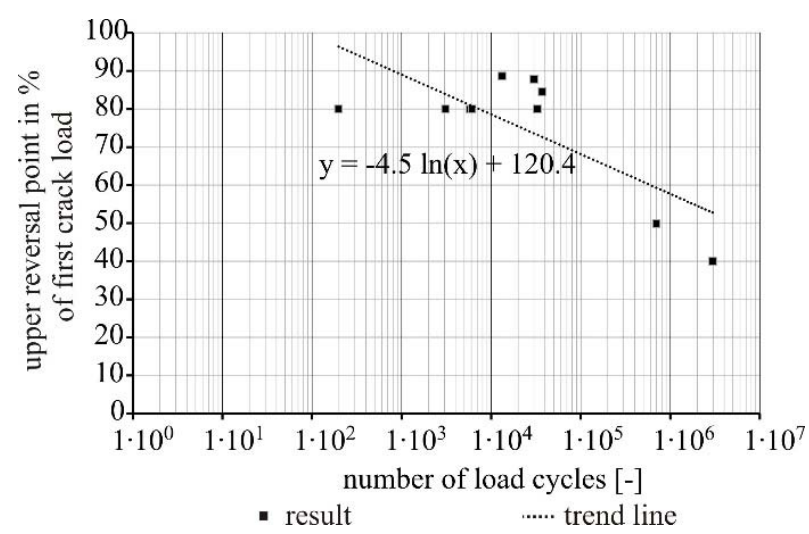

Figure 4: Number of load cycles until failure in the tension swelling tests as a function of the upper stress level

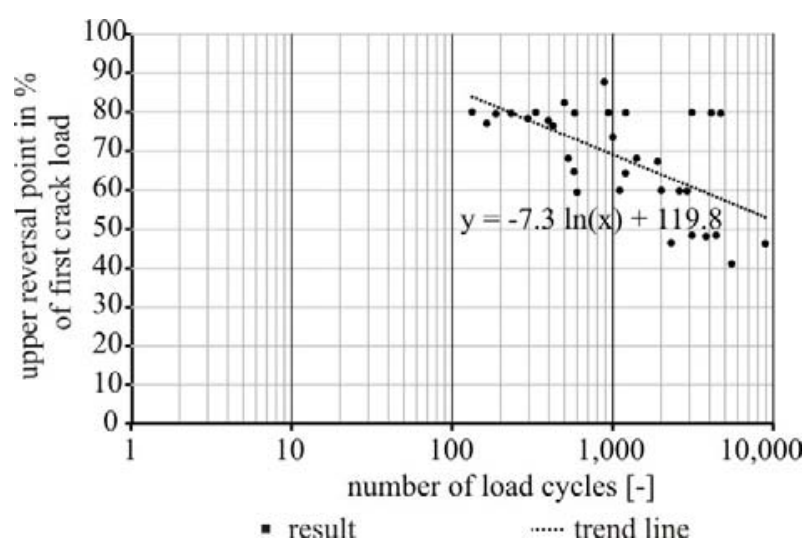

Figure 5: Number of load cycles until failure in the alternating tension-compression tests as a function of the upper stress level

The displayed trendlines do not fit to all values very properly. They rather have a descriptive charackter to display the overall and expected tendency, i.e. the increasing number of bearable load cycles with decreasing utilised stress bearing capacity. However, more experimental data is needed to suggest a precise mathematical description.

\subsection{Crack Pattern}

After mechanical testing, the crack pattern were analysed to give hints concerning the fracture mechanisms.

For this investigation, three different loading regimes were chosen: I_80_t, I_80_c and I_40_t. The corresponding images are shown in Figure 6 . The specimens tested in the first two regimes, both with high upper stresses showed a pronounced difference in the crack pattern. While specimens tested in the tension swelling regime exhibited a clear multiple cracks pattern, only one single crack was visible on the surface of the specimens tested in the alternating tension-compression regime. Similar picture could be observed for the specimens tested in the regime I_40_t. Obviously no multiple cracking could develop under the high-cycle fatigue tensile loading. 


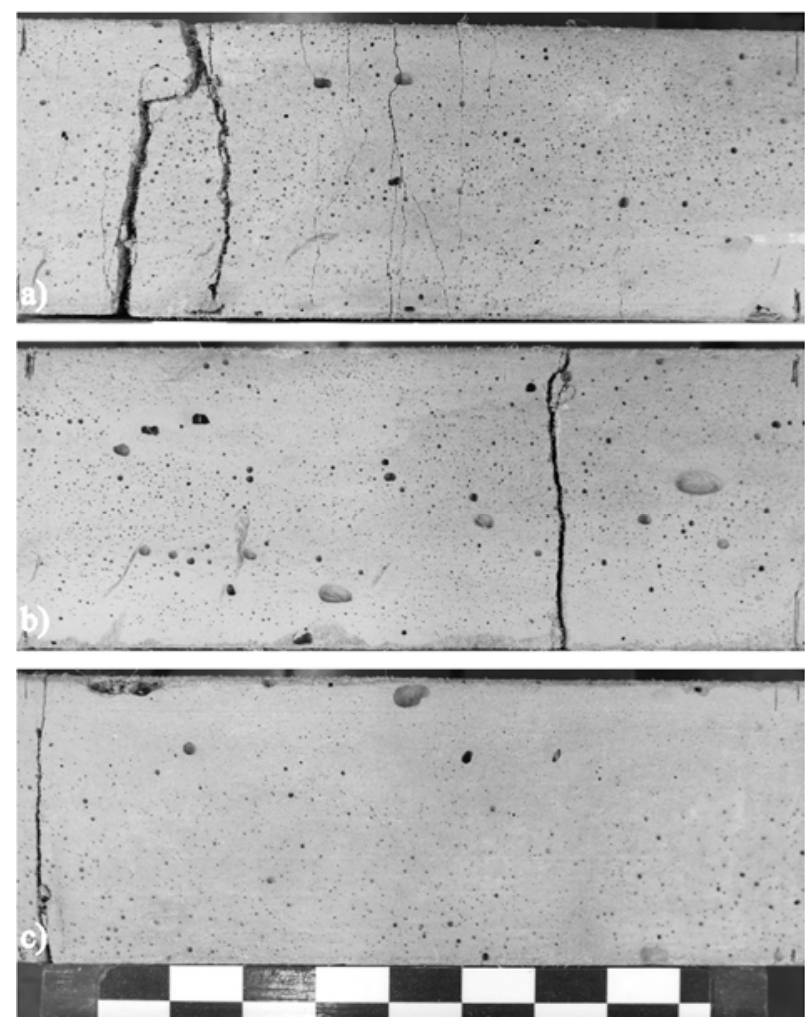

Figure 6: Typical crack pattern of specimens tested in various loading regimes: a) I_80_t, b) I_80_c, c) I_40_t

Regarding the development of the crack pattern three different mechanisms should be considered.

The first mechanism is the deterioration process in the crack plane. Caused by the cyclic loading the fibres bridging the crack are repeatedly pulled and released. Especially fibres inclined to crack plane may suffer damage due to friction and canting at crack edges. In the cases of tension-compression regime, fibres are additionally heavily squashed, which leads to a reduced load bridging capacity. Furthermore, the matrix is likely to be damaged by the repeating compression. The loose particles may exhibit additional damage potential for fibres.

The second mechanism is about the fatigue behaviour of the SHCC matrix. In the case when the stress level at the upper reversal point is high enough, the ongoing loading and unloading process leads to a growing of microcracks until they become a visible macro-crack. After the development of the matrix crack, fibres have to transfer the entire force in the crack plane, while micro-crack grow in the matrix is ongoing on other places of the SHCC specimen, preparing formation of further macro-cracks.

The third failure mechanism takes place in the fibre material itself, independent of the SHCC matrix. It is about the fatigue behaviour of the fibre described for example in [11].

For the specimens with only one crack obviously only the first and third mechanisms are valid. In case of loading regime I_80_t, also the second failure mechanism could be observed by the formation of new cracks with increasing number of loading cycles.

\subsection{Microscopic investigations}

For a better insight onto failure mechanisms, a detailed microscopic analysis of the crack surfaces was performed. Again, the specimens tested in the regimes I_80_t, I_80_c and I_40_t were chosen. The investigation was performed in a Scanning Electron Microscope (FEI Quanta Feg 250) run in the ESEM mode.

Figures 7-10 show images obtained for these three cyclic regimes. For the load regime I_80_t no special failure features was found in comparison to crack surfaces which are usually observed after monotonic uniaxial tension tests on SHCC. The matrix was still in sound condition, no additional cracks were observed, see Figure 7. The fibres were partly pulled-out and partly ruptured. However, no striations as a hint for fatigue failure [11] could be found.

For the cyclic regime I_80_c, with the same upper stress but with a moderate compression level $(8 \mathrm{MPa})$ at the lower reversal point, the crack surface has a completely different appearance (Figure 8). The matrix has a great number of cracks and seems to disaggregate on the crack surface and in its vicinity. Additionally, most of the fibres are destroyed which can be traced back to the complete closure of the crack and resulting crushing of fibres.

The specimens tested in the third loading regime (I_40_t) showed just one single crack in the crack pattern analysis, and in this sense were similar to the specimens tested in the regime I_80_c, see also Section 3.2. However, the microscopic images display a pronounced 


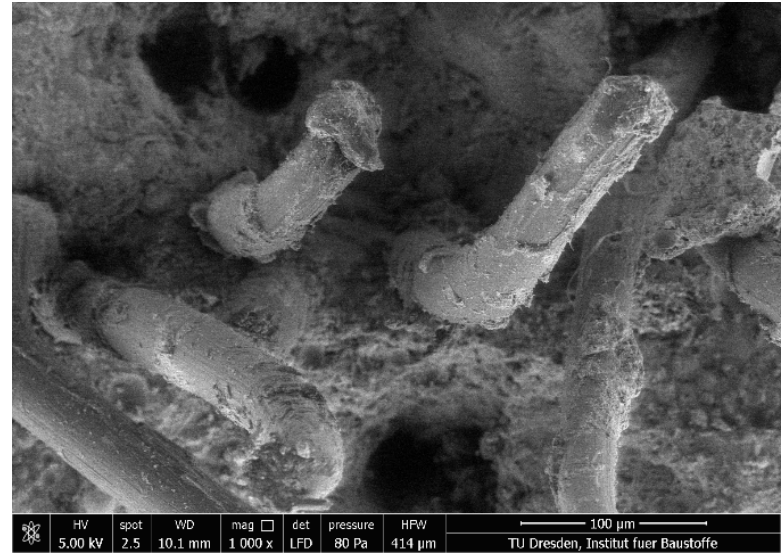

Figure 7: Crack surface of a specimen of I_80 t series

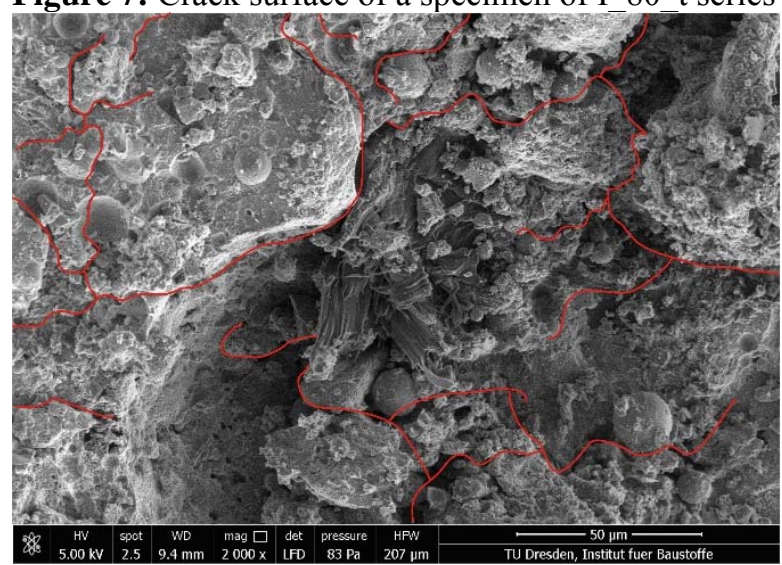

Figure 8: Crack surface of a specimen of I_80_c series

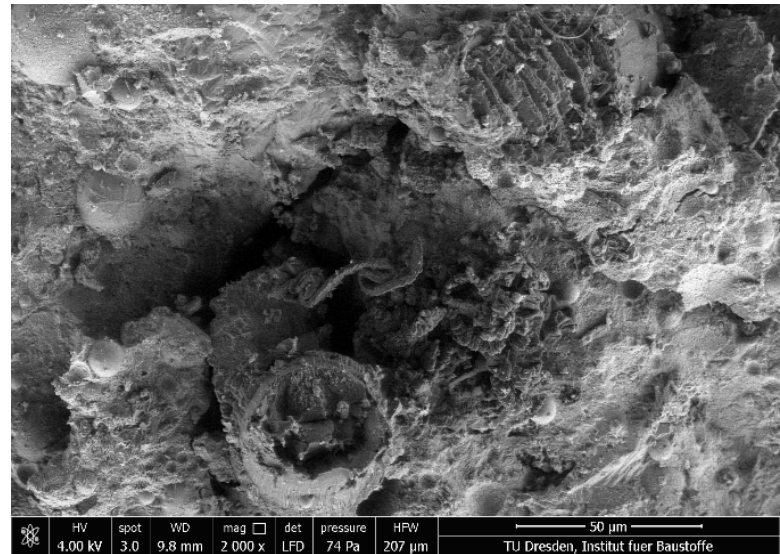

Figure 9: Crack surface of a specimen of I_40_t series

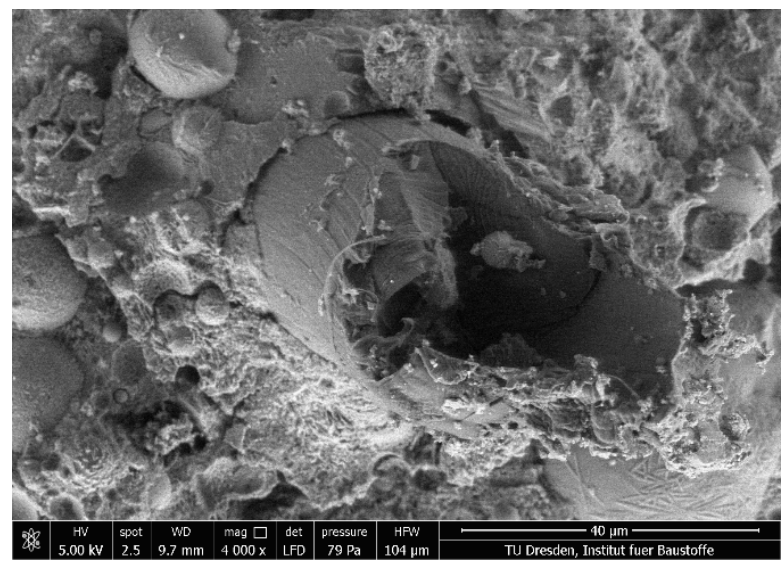

Figure 10: Detail of a broken fibre (I_40_t series) difference those obtained for fracture surfaces of the specimens tested in that alternating loading regime. The matrix shows no signs of deterioration, see Figure 9. The fibres are ruptured, but the rupture looks different to that what was found for the regime I_80_t. For many fibres a high damage degree of the inner part could be observed, see Figure 10, while the outer part of fibre was less affected. This features differ to those of usual appearance of failed fibres which narrow up to the breakage end. Furthermore, the internal failure planes in the fibre show striations. This is comparable to the beach marks typical for fatigue fracture surfaces of steel. These signs indicate a sever fatigue deterioration of the fibre material itself, which is well explicable due to a high number of cycles to failure in the series I_40_t.

\section{SUMMARY}

The paper at hand focuses on the cyclic behaviour of strain-hardening cement-based composites (SHCC) under force-controlled loading. For all tested setups the results scatter widely, which might be traced back to pronounced effects of even slight variations in SHCC properties (e.g., variations in the airvoids content and distribution, non-uniformity in fibre orientation etc.) on the number of loading cycles to failure. However, out of all results clear dependencies could be drawn. All specimens in alternating tension-compression loading regimes withstand a considerably lower number of load cycles in comparison to the specimens tested in pure tension regime. This results from the damage of fibres in the crack plane during the forceful closing of the crack in the compression part of the loop.

In the pure cyclic tension regime, formation of new cracks occurred at high upper stress levels, which were however, that of the first crack stress. This was caused by the fatigue behaviour of the matrix and the development of micro-cracks during cyclic loading.

A specific failure mode was found on the crack surface of the specimens loaded with 40 $\%$ of the first crack stress in the tension swelling loading regime. In contrast to the 
typical PVA-fibre failure with narrowed ruptured endings, an inner damage leading to failure was observed. The inner part of the fibre showed striations comparable to the beach lines on fatigue crack surfaces of steel. This appearance may help to differentiating between two fibre failure mechanisms: tensile rupture due to overloading and fatigue failure.

\section{ACKNOWLEDGEMENTS}

The authors gratefully acknowledge the financial support by the Deutsche Forschungsgemeinschaft (DFG) and the Bundesanstalt für Straßenwesen (BASt). Furthermore, the authors thank Prof. Frohmut Wellner and Ms. Katrin Paschke at the Institute of Urban and Pavement Engineering at the TU Dresden for the experimental support and fruitful discussions.

\section{REFERENCES}

[1] Li, V. C.: From micromechanics to structural engineering - The design of cementitious composites for civil engineering applications. JSCE J. of Structure Mechanics and Earthquake Engineering 10 (2), 1993, pp. 37-48

[2] Fischer G.; Li, V. C. (eds.): Int. RILEM Workshop on HPFRCC in Structural Applications. Honolulu, RILEM Proceedings PRO 49, RILEM Publications S.A.R.L., 2006

[3] Toledo Filho, R.D.; Silva, F.A.; Koenders, E.A.B.; Fairbairn, E.M.R. (eds.): Strain Hardening Cementitious Composites (SHCC2-Rio). Rio de Janeiro, RILEM Proceedings PRO 81, RILEM Publications S.A.R.L., 2011.

[4] Schlangen, E.; Sierra Beltran, M.G.; Lukovic, M.; Ye, G. (eds.): SHCC3 - $3^{\text {rd }}$ International RILEM Conference on Strain Hardening Cementitious Composites. Dordrecht, RILEM Proceedings PRO 97, RILEM Publications S.A.R.L., 2014

[5] Fukuyama, H.; Haruhiko, S.; Yang, I.: HPFRCC Damper for Structural Control. In: Proceedings of the JCI International Workshop on Ductile Fiber Reinforced Cementitious Composites (DFRCC). Takayama, Japan, Japan Concrete Institute, 2002, pp. 219-228

[6] Douglas, K. S.; Billington, S. L.: Ratedependence in high-performance fiberreinforced cement-based composites for seismic applications. Fischer G.; Li, V. C. (eds.): Int. RILEM Work-shop on HPFRCC in Structural Applications. Honolulu, 2005, RILEM Publications S.A.R.L., PRO 49, 2006, pp. 17-26

[7] Jun, P.; Mechtcherine, V.: Behaviour of Strain-hardening cement-based composites (SHCC) under monotonic and cyclic tensile loading; Part 1 - Experimental investigations. Cement and Concrete Composites 32, 2010, pp. 801-809

[8] Mechtcherine, V.; Silva, F. A.; Butler, M.; Zhu, D.; Mobasher, B.; Gao, S.-L.; Mäder, E.: Behaviour of strain-hardening cement-based composites under high strain rates. Journal of Advanced Concrete Technology, 9(1), 2011, pp. 51-62.

[9] Mechtcherine V.; Silva F.; Müller S.; Jun P.; Toledo Filho R.: Coupled strain rate and temperature effects on the tensile behaviour of strain- hardening cement- based composites (SHCC) with PVA fibres. Cement and Concrete Research 42, 2012, pp. 1417-1427

[10] Müller S.; Mechtcherine V.: High- cycle fatigue of Strain-Hardening Cement-BasedComposites (SHCC). Schlangen, E.; Sierra Beltran M.G.; Lukovic, M.; Ye, G. (eds): SHCC3 3rd international RILEM conference on strain hardening cementitious composites. RILEM Proceedings PRO 97, RILEM Publications S.A.R.L., 2014, pp. 137-144

[11] Qui J., Yang E.-H.: Study on fatigue failure of polymeric fibre-reinforced Strain-Hardening Cementitious Composites. Schlangen, E.; Sierra Beltran M.G.; Lukovic, M.; Ye, G. (eds): SHCC3 3rd international RILEM conference on strain hardening cementitious composites. RILEM Proceedings PRO 97, RILEM Publications S.A.R.L., 2014, pp. 145153 